\title{
Conventional and Inverse Magnetocaloric Effect in Ni-Rich Ni-Mn-Ga and Ni-Mn-Sn Heusler Alloy: A Comparison
}

\author{
D. Pal ${ }^{*}$ \\ Department of Physics, Kandi Raj College, Kandi, Murshidabad, West Bengal, India, PIN-742137
}

Received 2 December 2019, accepted in final revised form 20 January 2020

\begin{abstract}
Magnetic and magnetocaloric effect of Ni-rich $\mathrm{Ni}_{52} \mathrm{Mn}_{34} \mathrm{Sn}_{14}(\mathrm{Ni}-\mathrm{Mn}-\mathrm{Sn})$ and $\mathrm{Ni}_{54} \mathrm{Mn}_{17} \mathrm{Ga}_{29}$ (Ni-Mn-Ga) Heusler alloys have been investigated up to a magnetic field of $5 \mathrm{~T}$ and within a temperature range of $4.2-325 \mathrm{~K}$. In this study, we report a systematic comparison between Ni-rich $\mathrm{Ni}_{52} \mathrm{Mn}_{34} \mathrm{Sn}_{14}$ and $\mathrm{Ni}_{54} \mathrm{Mn}_{17} \mathrm{Ga}_{29}$ alloys in the light of their magnetocaloric effect (MCE). In both the samples, a large magnetic entropy change was observed $\left(\sim 96 \mathrm{~J} \mathrm{~kg}^{-1} \mathrm{~K}^{-1}\right.$ for Ni-Mn-Ga), but for the alloy Ni-Mn-Sn the MCE becomes negative/inverse. From various magnetic measurements it have been observed that in Ni-Mn-Sn alloy the martensite to austenite transition accompanied by lower to higher magnetization whereas for $\mathrm{Ni}-\mathrm{Mn}-\mathrm{Ga}$ alloy reverse situation occurred. The different type of magnetocaloric effect, i.e. inverse and direct can be explained by considering magneto-crystalline anisotropy and different state of magnetization of the martensite and austenite phase of the alloys.
\end{abstract}

Keywords: Heusler alloy; MCE; Martensitic transition; Magnetic entropy.

() 2020 JSR Publications. ISSN: 2070-0237 (Print); 2070-0245 (Online). All rights reserved. doi: http://dx.doi.org/10.3329/jsr.v12i3.44357

J. Sci. Res. 12 (3), 303-310 (2020)

\section{Introduction}

During last few years the area of research in ferromagnetic shape memory alloys (FSMAs) have been attracted immense attention due to its multifunctional properties such as magnetic shape memory effect [1], large magnetocaloric effect (MCE) [2,3], giant magnetoresistance [4,5], etc. The alloys with composition Gd-Si-Ge, Ni-Mn-Z ( $\mathrm{Z}=\mathrm{Ga}, \mathrm{Al}$, $\mathrm{In}, \mathrm{Sn}, \mathrm{Sb}), \mathrm{La}-\mathrm{Fe}-\mathrm{Si}$ and $\mathrm{Mn}-\mathrm{Fe}-\mathrm{P}-\mathrm{As}$ are very useful in this field of study [1-8]. Offstoichiometric composition of Ni-Mn-Z (Z=In, Sn, Sb) Heusler alloys are the most studied magnetocaloric materials among the FSMAs as they show large magnetic entropy change due to magnetic and magneto-structural transitions [9]. These alloys show a positive value of temperature derivative of magnetization near the structural transition temperature, as a result of which isothermal magnetic entropy change $\left(\Delta \mathrm{S}_{\mathrm{M}}\right)$ becomes positive and adiabatic temperature change $\left(\Delta \mathrm{T}_{\mathrm{ad}}\right)$ gets negative value. So the samples cool down when an external magnetic field applied adiabatically (known as inverse MCE). Some Heusler alloys such as Ni-Fe-Ga, Ni-Mn-Ga shows shape memory effect as well as large

\footnotetext{
${ }^{*}$ Corresponding author: deba.phy@gmail.com
} 
magnetocaloric effect (MCE) [10,11]. The temperature derivative of magnetization of these alloys is negative as in the case of regular ferromagnetic materials. Therefore from the thermodynamic formulation isothermal magnetic entropy change $\left(\Delta \mathrm{S}_{\mathrm{M}}\right)$ becomes negative and adiabatic temperature change $\left(\Delta \mathrm{T}_{\mathrm{ad}}\right)$ gets positive. The samples get heated when an external magnetic field applied adiabatically (known as conventional/direct MCE).

During heating both stoichometric and off-stoichometric compounds with composition close to $\mathrm{Ni}_{2} \mathrm{MnGa}$ undergo a first-order structural transition from martensite phase (tetragonal structure) to austenite phase (cubic structure) and the reverse process occurs on cooling $[12,13]$. This structural transition brings about fundamental differences in the magnetic properties of low-temperature martensite and high-temperature austenite state, causing an abrupt change in magnetization. There may be different possible martensite structures such as non-modulated (termed as NM), five layer modulated (10 $\mathrm{M})$, seven layer modulated (14 M) as well as six-layer modulated martensite [14]. The structural and magnetic phase transitions in these alloys can be tuned by varying the composition of the alloys. Most of the functional properties of these alloys are associated with the magneto-structural transition from high temperature austenite to energetically favorable low temperature martensite phase [1-5] which is an important property of these alloys. By varying composition or by substituting suitable atoms in the place of $\mathrm{Ni}, \mathrm{Mn}$ or $\mathrm{Z}$ atoms the structural instability associated with the field-induced first order structural transition can also be tuned in these alloys. In stoichiometric Heusler structure, Ni atoms occupy the octahedral $(0,0,0)$ and $(1 / 2,1 / 2,1 / 2)$ sites. Mn and $\mathrm{Z}(=\mathrm{Ga}, \mathrm{Sn})$ atoms occupy the $(1 / 4,1 / 4,1 / 4)$ and $(3 / 4,3 / 4,3 / 4)$ tetrahedral sites respectively [15]. In case of off-stoichiometric Mn rich Heusler alloys, excess Mn atoms occupy the regular $\mathrm{Ni}, \mathrm{Z}$ or both $\mathrm{Ni}$ and $\mathrm{Z}$ sites depending on the compositions. These excess $\mathrm{Mn}$ atoms in the Ni sites behave ferromagnetically, which lowers the martensitic transition temperature $\left(\mathrm{T}_{\mathrm{M}}\right)$, but $\mathrm{Mn}$ atoms in the $\mathrm{Z}$ sites couple antiferromagnetically to the nearest $\mathrm{Mn}$ atoms in the regular Mn sites. This in turn shifts the structural transition to the higher temperatures. As the slope of the structural transition becomes sharper, MCE increases abruptly.

In our earlier work we reported large value of inverse magnetocaloric effect and magnetoresistance in Ni-rich $\mathrm{Ni}_{52} \mathrm{Mn}_{34} \mathrm{Sn}_{14}$ polycrystalline alloy [16]. In the present work, nickel-rich $\mathrm{Ni}_{54} \mathrm{Mn}_{17} \mathrm{Ga}_{29}$ polycrystalline alloy was prepared and studied to understand the effect of substituting $\mathrm{Mn}$ with $\mathrm{Ni}$ on the structural and magnetic transition. Also we report a large magnetocaloric effect (MCE) in $\mathrm{Ni}_{54} \mathrm{Mn}_{17} \mathrm{Ga}_{29}$ Heusler alloy in the vicinity of its magneto-structural transition. Magnetic properties of those samples have also been investigated in details to explain and compare the different type of state of magnetization and magnetocrystalline anisotropy in martensite and austenite phase.

\section{Experimental}

The $\mathrm{Ni}_{54} \mathrm{Mn}_{17} \mathrm{Ga}_{29}$ Heusler alloy was prepared by conventional arc melting technique in a 4N purity Argon atmosphere. The obtained ingot was wrapped with a Ta foil and homogenized in a highly evacuated sealed quartz ampoule at $1173 \mathrm{~K}$. After $24 \mathrm{~h}$ of 
annealing, the ampoule was quenched in ice water. The nominal composition was checked by energy-dispersive spectroscopy (EDS). To characterize the crystallographic phase of the sample X-ray diffraction pattern was carried out using $\mathrm{CuK}_{\alpha}$ radiation as depicted in Fig. 1. At room temperature the sample was found to be completely cubic-austenite phase. The structural transition temperatures were estimated from differential scanning calorimetry (DSC) measurement. Magnetic measurements were performed using a superconducting quantum interference device (SQUID) magnetometer up to 5T magnetic fields.

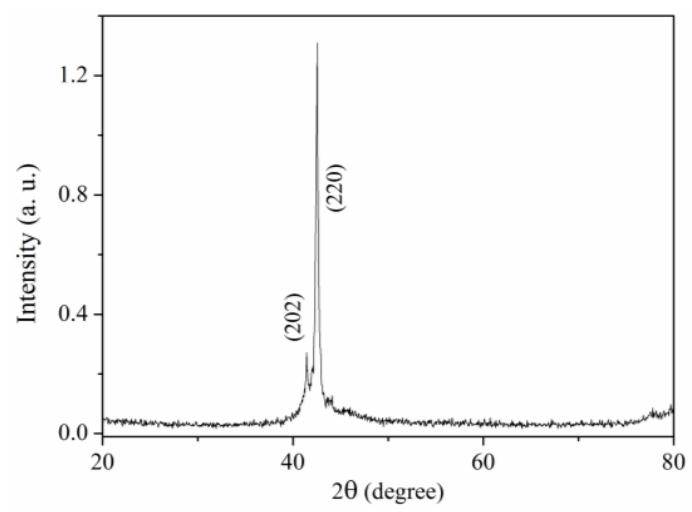

Fig. 1. Powder x-ray diffraction pattern of $\mathrm{Ni}_{54} \mathrm{Mn}_{17} \mathrm{Ga}_{29}$ alloy at room temperature.

\section{Results and Discussion}

Fig. 1 shows powder x-ray diffraction pattern of the alloy $\mathrm{Ni}_{54} \mathrm{Mn}_{17} \mathrm{Ga}_{29}$ at room temperature. The sample shows cubic $\mathrm{L} 2_{1}$ (space group $\mathrm{Fm} 3 \mathrm{~m}$ ) structure at room temperature which is similar as reported for $\mathrm{Ni}_{52} \mathrm{Mn}_{34} \mathrm{Sn}_{14}$ alloy [16]. Magnetization vs temperature curves of sample $\mathrm{Ni}_{54} \mathrm{Mn}_{17} \mathrm{Ga}_{29}$ have been shown in Fig. 2. On cooling, a ferromagnetic transition takes place at the Curie temperature $\mathrm{T}_{\mathrm{C}}=301 \mathrm{~K}$ with a sudden large increase in magnetization. A sharp downward jump occurs at a temperature of $277 \mathrm{~K}$ indicating the start of martensitic transformation from austenite to martensite phase. On further cooling, again an abrupt increase of magnetization is observed around a temperature of $199 \mathrm{~K}$ revealing another distinct structural transformation called intermartensitic transformation.

The latter transformation is usually observed in alloys with $\mathrm{T}_{\mathrm{M}}$ near or higher than room temperature and is found to be a first-order phase transformation between martensites with different structures at temperatures lower than $\mathrm{T}_{\mathrm{M}}$. In the similar fashion as calculated for the other sample [16] the austenitic transition is given by, $T_{A}=\left(A_{s}+A_{f}\right) / 2$ $=292 \mathrm{~K}$ and for martensitic transition, $\mathrm{T}_{\mathrm{M}}=\left(\mathrm{M}_{\mathrm{s}}+\mathrm{M}_{\mathrm{f}}\right) / 2=288 \mathrm{~K}$. For $\mathrm{Ni}_{54} \mathrm{Mn}_{17} \mathrm{Ga}_{29}$, the two transition temperatures (martensitic transformation temperatures and ferro-para Curie temperature $T_{C}$ ) almost coincide with each other. The increase of $T_{M}$ in these Ni-Mn-Ga alloys with nickel content is attributable to the increase in electron concentration e/a due 
to the Hume-Rothery mechanism [17]. The e/a value of the alloy have been calculated with 10 valence electrons per atom for $\mathrm{Ni}, 7$ for $\mathrm{Mn}$, and 3 for $\mathrm{Ga}$ and it is found to be 7.46, which is also consistent with the increase of $\mathrm{T}_{\mathrm{M}}$ as reported by other researchers [18]. The lowering of $T_{C}$ of the sample is due to the dilution of magnetic moment located on $\mathrm{Mn}$ atoms $[17,19]$.

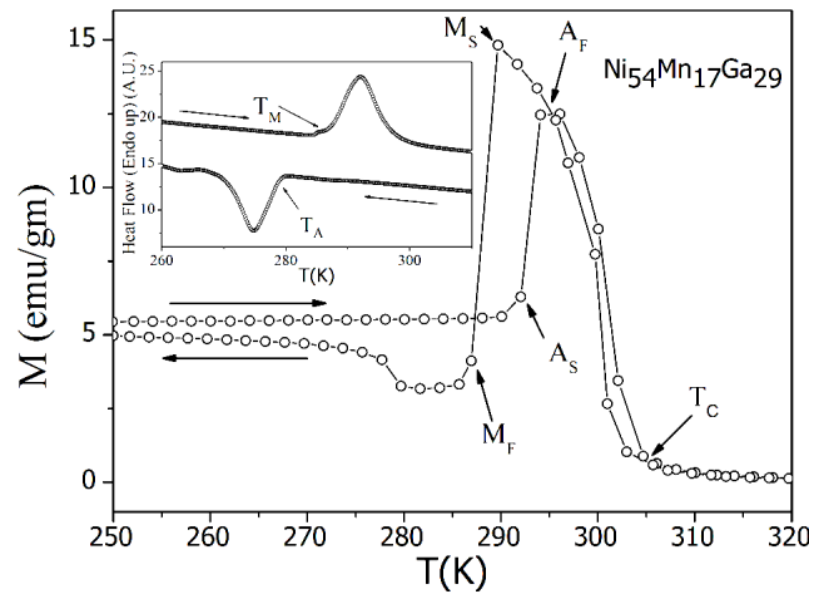

Fig. 2. Thermomagnetic curves in ZFC condition under 100 Oe magnetic fields and DSC curves (inset) for $\mathrm{Ni}_{54} \mathrm{Mn}_{17} \mathrm{Ga}_{29}$ alloy.

In our previous reported work, from thermomagnetic curves in ZFC condition it was observed that the sample $\mathrm{Ni}_{52} \mathrm{Mn}_{34} \mathrm{Sn}_{14}$ undergoes martensite-austenite structural transition near $220 \mathrm{~K}$ on heating and reverse transition on cooling near $205 \mathrm{~K}$ along with ferro-para magnetic transition at $\mathrm{T}_{\mathrm{C}}=305 \mathrm{~K}$ (Curie temperature). The martensite to austenite transition's starting and end temperatures are found at $220 \mathrm{~K}\left(\mathrm{~A}_{\mathrm{s}}\right)$ and $235 \mathrm{~K}\left(\mathrm{~A}_{\mathrm{f}}\right)$ respectively. The reverse transition i.e. martensite start begins at $M_{s}=220 \mathrm{~K}$ and ends at $\mathrm{M}_{\mathrm{f}}=205 \mathrm{~K}$. Accordingly, the temperature of austenitic transition is given by, $\mathrm{T}_{\mathrm{A}}=$ $\left(\mathrm{A}_{\mathrm{s}}+\mathrm{A}_{\mathrm{f}}\right) / 2=227.5 \mathrm{~K}$ and for martensitic transition, $\mathrm{T}_{\mathrm{M}}=\left(\mathrm{M}_{\mathrm{s}}+\mathrm{M}_{\mathrm{f}}\right) / 2=212.5 \mathrm{~K}$. We could not observe the $T_{C}$ from $M$ vs $T$ data for the sample as ferro-para curie transition $\left(T_{C}\right)$ is far from room temperature which is beyond of our range of measurement. The martensiteaustenite transition temperature of our sample is much lower than the reported value of $\mathrm{Ni}_{50} \mathrm{Mn}_{36} \mathrm{Sn}_{14}$ alloy [20]. This is due to the addition of extra $\mathrm{Ni}$ atoms in the regular $\mathrm{Mn}$ sites. In off-stoichiometric Heusler structure the Mn atoms in regular Mn site interact antiferromagnetically with the excess $\mathrm{Mn}$ atoms in the $\mathrm{Sn}$ site. This AFM interaction stabilizes the martensite phase to a higher temperature. It is well known that $\mathrm{Ni}$, Co or $\mathrm{Fe}$ substitution in Mn site enhances the ferromagnetic exchange interaction and diminishes antiferromagnetic coupling between $\mathrm{Mn}$ atoms in regular $\mathrm{Mn}$ sites and $\mathrm{Mn}$ atoms in $\mathrm{Sn}$ sites in both the martensite and austenite phase, which in turns decreases the $T_{M}$. This supports the lower value of martensite-austenite transition temperature in our sample with respect to $\mathrm{Ni}_{50} \mathrm{Mn}_{36} \mathrm{Sn}_{14}$ alloy. However it is believed that the martensitic transition $\mathrm{T}_{\mathrm{M}}$ increases with the increase of the valance electron concentration (e/a), but recent reports 
showed that it actually depends on the hybridization of 3d states of $\mathrm{Ni}$ and $\mathrm{Mn}$. Ye et. al. [21] suggested for $\mathrm{Ni}_{2} \mathrm{Mn}_{1+\mathrm{x}} \mathrm{Sn}_{1-\mathrm{x}}$ alloys that a strong hybridization exists between $\mathrm{Ni} 3 \mathrm{~d}$ states and $3 \mathrm{~d}$ states of $\mathrm{Mn}$ at the non-magnetic Sn site. It is demonstrated that after the establishment of hybridization, any change in $\mathrm{Ni}$ or $\mathrm{Mn}$ content is responsible for weakening of the hybridization [18]. This is responsible for the decrease of $T_{M}$.

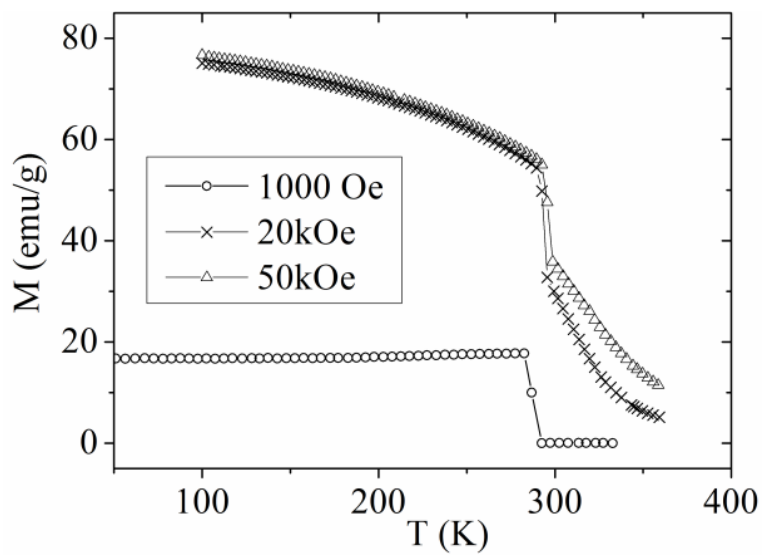

Fig. 3. ZFC thermomagnetic curves for $\mathrm{Ni}_{54} \mathrm{Mn}_{17} \mathrm{Ga}_{29}$ alloy in the presence of $0.1 \mathrm{~T}, 2 \mathrm{~T}$ and $5 \mathrm{~T}$ magnetic field.

The magnetization vs temperature curves for the sample $\mathrm{Ni}_{54} \mathrm{Mn}_{17} \mathrm{Ga}_{29}$ from $100 \mathrm{~K}$ to $350 \mathrm{~K}$ at different magnetic fields of $0.1 \mathrm{~T}, 2 \mathrm{~T}$, and $5 \mathrm{~T}$ are shown in Fig. 3. All the magnetic iso-field curves are similar in nature. Throughout the applied magnetic field which is relatively high the martensite to austenite transition was accompanied by higher to lower magnetization whereas reverse situation observed for low magnetic field (Fig. 2). The saturation magnetization in the martensite phase is obtained by much higher magnetic field compared to austenite phase because of the large magnetocrystalline anisotropy constant [22]. Hence in the austenite phase the moment saturated in relatively low field but for the other phase it is not saturated, consequently the martensite to austenite transition accompanied by higher to lower magnetization which results a negative value of temperature derivative of magnetization in contrary to $\mathrm{Ni}_{52} \mathrm{Mn}_{34} \mathrm{Sn}_{14}$ alloy [16].

From the magnetization vs temperature curves for the sample $\mathrm{Ni}_{52} \mathrm{Mn}_{34} \mathrm{Sn}_{14}$ at different magnetic fields of $1 \mathrm{~T}, 2 \mathrm{~T}, 3 \mathrm{~T}, 4 \mathrm{~T}$, and $5 \mathrm{~T}$ it have been observed that all the magnetic iso-field curves are similar in nature [16]. Throughout the applied magnetic field the martensite to austenite transition was accompanied by lower to higher magnetization which results a positive value of temperature derivative of magnetization and consequently inverse MCE obtained as $\triangle \mathrm{S}$ becomes positive. It is also observed that the transition point shifts towards the lower temperatures as we go towards the higher field curves. Field-induced first order magneto-structural transition (FOMST) is evident from the shift of transition points towards the lower temperatures with the increasing magnetic fields. The shift in transition temperature per applied fields was calculated as $\Delta \mathrm{T} / \Delta \mathrm{H} \approx$ 
$1 \mathrm{~K} / \mathrm{T}$. From the magnetic isotherms $\left(\mathrm{M}\right.$ vs $\mathrm{H}$ ) of the sample a large $\Delta \mathrm{S}_{\mathrm{M}} \approx-8 \mathrm{~J} \mathrm{~kg}^{-1} \mathrm{~K}^{-1}$ obtained at $225 \mathrm{~K}$ (very close to $\mathrm{T}_{\mathrm{M}}$ ) using the Maxwell's thermodynamic equation [4] under the applied magnetic fields of $3 \mathrm{~T}$ which has also been reported. The hysteresis behavior observed within the temperatures from 223 to $232 \mathrm{~K}$. The thermal hysteresis due to structural transition coupled with the magnetic domains of the sample. This is responsible for this type of hysteretic nature. The value of saturation magnetizations difference between martensitic and austenite state $\left(\Delta M=M_{\text {Martensitic }}-M_{\text {Austenite }}\right)$ is also increased with increasing $\mathrm{Ni}$ content. A large difference in saturation magnetization between two successive magnetic isotherms can be observed for the alloy which is responsible for the larger inverse magnetocaloric effect in $\mathrm{Ni}_{52} \mathrm{Mn}_{34} \mathrm{Sn}_{14}$ with respect to $\mathrm{Ni}_{50-\mathrm{x}} \mathrm{Mn}_{36+\mathrm{x}} \mathrm{Sn}_{14}$ alloys.

At both the structural states (martensite and austenite) excess $\mathrm{Ni}$ atoms increase the $\mathrm{Ni}-\mathrm{Mn}$ and $\mathrm{Mn}-\mathrm{Mn}$ ferromagnetic exchange interaction. The Mn-excess and $\mathrm{Mn}$ atoms interact ferromagnetically at the austenite state and antiferromagnetically at the martensite state $[23,24]$, which probably causes a large difference in saturation magnetization $(\Delta M)$ between the two states. As we know for first-order magnetic phase transitions the magnetic Clausius-Clapeyron equation is also valid and to estimate entropy change one can use it. We have also estimated the $\Delta \mathrm{S}_{\mathrm{M}}$ from Clasius-Clapeyron equation (eq. 1) [25].

$\Delta \mathrm{H} / \Delta \mathrm{T}=-\Delta \mathrm{S}_{\mathrm{M}} / \Delta \mathrm{M}$

Where $\Delta \mathrm{M}=\mathrm{M}_{\text {Martensite }}-\mathrm{M}_{\text {Austenite }}$ and $\Delta \mathrm{H} / \Delta \mathrm{T}$ is the average temperature shift of the transition point with increasing field. A much higher value of $\Delta S_{\mathrm{M}}(\approx 18 \mathrm{~J} / \mathrm{kg} \mathrm{K})$ was derived with $\Delta \mathrm{H} / \Delta \mathrm{T} \approx 1 \mathrm{TK}^{-1}$ and $\Delta \mathrm{M} \approx 18 \mathrm{emu} \mathrm{g}^{-1}$ at $\mathrm{H}=3 \mathrm{~T}$ by using Clasius-Clapeyron equation [16].

Magnetic isotherms of the sample $\mathrm{Ni}_{54} \mathrm{Mn}_{17} \mathrm{Ga}_{29}$ around their magnetic and structural transition temperatures were measured at $0.5 \mathrm{~K}$ temperature intervals within the temperature range from $287 \mathrm{~K}$ to $292 \mathrm{~K}$ and up to a maximum magnetic field of 5T shown in Fig. 4. The change in magnetic entropy $\left(\Delta \mathrm{S}_{\mathrm{M}}\right)$ due to a field change of $0-5 \mathrm{~T}$ has been calculated from these curves using the Maxwell's thermodynamic relations in similar way.

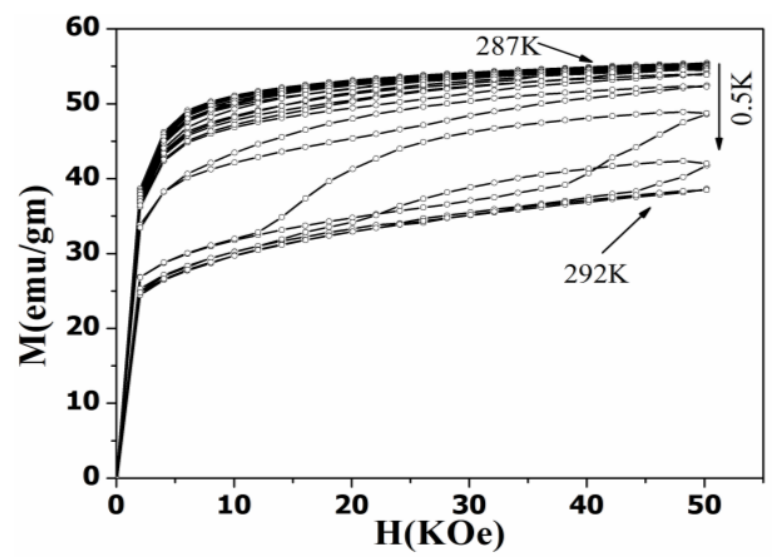

Fig. 4. Magnetic isotherms for $\mathrm{Ni}_{54} \mathrm{Mn}_{17} \mathrm{Ga}_{29}$ alloy from $287 \mathrm{~K}$ to $292 \mathrm{~K}$ at the interval of $0.5 \mathrm{~K}$. 
Large change in magnetization with temperature along with significant hysteresis effect is observed within $290 \mathrm{~K}$ and $292 \mathrm{~K}$. Maximum value of $\Delta \mathrm{S}_{\mathrm{M}}$ calculated using Maxwell's equation are found to be $-96 \mathrm{~J} \mathrm{~kg}^{-1} \mathrm{~K}^{-1}$ at $290.75 \mathrm{~K}$ with $\Delta \mathrm{T}=0.5 \mathrm{~K}$. Large change in $\Delta \mathrm{S}_{\mathrm{M}}\left(-86 \mathrm{~J} \mathrm{~kg}^{-1} \mathrm{~K}^{-1}\right)$ in single crystals of Ni-Mn-Ga Heusler alloys was also reported earlier [24]. In $\mathrm{Ni}_{54} \mathrm{Mn}_{17} \mathrm{Ga}_{29}$ both $\mathrm{T}_{\mathrm{C}}$ and $\mathrm{T}_{\mathrm{M}}$ are very close to each other [Fig. 2] which may be responsible for large change in $\Delta \mathrm{S}_{\mathrm{M}}$. Metamagnetic like transition along with large hysteresis observed in $\mathrm{M}$ vs $\mathrm{H}$ curves of this sample is perhaps due to fieldinduced transitions from paramagnetic austenite to ferromagnetic martensite. Large change in $\Delta \mathrm{S}_{\mathrm{M}}$ shown by the same alloy is caused by the combination of martensitic and magnetic transitions [26]. Isothermal magnetic entropy change $\left(\Delta \mathrm{S}_{\mathrm{M}}\right)$ has also been estimated from Fig. 3 using Clausius-Clapeyron equation. In Fig. 3, with $d H / d T \sim 1.17$ T/K and $\Delta \mathrm{M} \sim 18$ emu g ${ }^{-1}$ at $\mathrm{H}=0.1 \mathrm{~T}, \Delta \mathrm{S}_{\mathrm{M}}$ was found to be around $-21 \mathrm{~J} \mathrm{~kg}^{-1} \mathrm{~K}^{-1}$, much less than that calculated from Fig. 4 . The cause of the discrepancy may be due to the error in both the methods of calculation [25].

\section{Conclusion}

We have discussed the conventional and inverse MCE in nickel rich $\mathrm{Ni}_{54} \mathrm{Mn}_{17} \mathrm{Ga}_{29}$ and $\mathrm{Ni}_{52} \mathrm{Mn}_{34} \mathrm{Sn}_{14}$ Heusler alloy. Both the alloys showed large MCE. The coincidence of martensite-austenite structural transition temperature and the ferro-paramagnetic transition temperature may be an important criterion for enhancement of MCE as observed in $\mathrm{Ni}_{54} \mathrm{Mn}_{17} \mathrm{Ga}_{29}$ alloy. For the alloy $\mathrm{Ni}_{52} \mathrm{Mn}_{34} \mathrm{Sn}_{14}$ large inverse MCE has been observed in the vicinity of FOMST. The enhanced ferromagnetic exchange interaction due to addition of excess nickel has been observed in this alloy. Proper substitution in $\mathrm{Ni}, \mathrm{Mn}$ or $\mathrm{Z}$ site can produce large inverse magnetocaloric effect which may be used in the magnetic refrigerators with a fine tuning in FOMST.

\section{Acknowledgements}

A part of this work was performed at S. N. Bose National Centre for Basic Sciences, Kolkata.

\section{References}

1. R. Kainuma, Y. Imano, W. Ito, Y. Sutou, H. Morito, S. Okamoto, O. Kitakami, K. Oikawa, A. Fujita, T. Kanomata, and K. Ishida, Nature (London) 439, 957 (2006).

https://doi.org/10.1038/nature04493

2. T. Krenke, E. Duman, M. Acet, E. F. Wassermann, X. Moya, L. Manosa, and A. Planes, Nature Mater. 4, 450 (2005). https://doi.org/10.1038/nmat1395

3. N. V. R. Rao, R. Gopalan, V. Chandrasekaran, and K. G. Suresh, Appl. Phys. A 99, 265 (2010). https://doi.org/10.1007/s00339-009-5517-3

4. D. Pal and K. Mandal, J. Phys. D: Appl. Phys. 43, ID 455002 (2010). https://doi.org/10.1088/0022-3727/43/45/455002

5. R. Sahoo, A. K. Nayak, K. G. Suresh, and A. K. Nigam, J. Magn. Magn. Mater. 324, 1267 (2012). https://doi.org/10.1016/j.jmmm.2011.11.025 
6. V. K. Pecharsky and K. A. Gschneidner Jr. Phys. Rev. Lett. 78, 4494 (1997). https://doi.org/10.1103/PhysRevLett.78.4494

7. F. Hu, B. Shen, J. Sun, Z. Cheng, G. Rao, and X. Zhang, Appl. Phys. Lett. 78, 3675 (2001). https://doi.org/10.1063/1.1375836

8. N. H. Dung, L. Zhang, Z. Q. Ou, and E. Brück, Scripta Mater. 67, 975 (2012). https://doi.org/10.1016/j.scriptamat.2012.08.036

9. K. Mandal, D. Pal, N. Scheerbaum, J. Lyubina, and O. Gutfleisch, IEEE Trans. Magn. 44, 2993 (2008). https://doi.org/10.1109/TMAG.2008.2002481

10. V. Recarte, J. I. Perez-Landazabal, C. Gomez-Polo, E. Cesariand, and J. Dutkiewicz, Appl. Phys. Lett. 88, ID 132503 (2006). https://doi.org/10.1063/1.2189665

11. K. Mandal, D. Pal, N. Scheerbaum, J. Lyubina, and O. Gutfleisch, J. Appl. Phys. 105, ID 073509 (2009). https://doi.org/10.1063/1.3099596

12. Y. Li, C. Jiang, T. Liang, Y. Ma, and H. Xu, Scripta Mater. 48, 1255 (2003). https://doi.org/10.1016/S1359-6462(03)00048-4

13. F. Alvarado-Hernandez, D. E. Soto-Parra, R. Ochoa-Gamboa, P. O. Castillo-Villa, H. FloresZuniga, and D. Rios-Jara, J. Alloys Comp, 462, 442 (2008). https://doi.org/10.1016/j.jallcom.2007.08.075

14. K. Oikawa, T. Ota, Y. Sutou, T. Ohmori, R. Kainuma, and K. Ishida, Mater. Trans. 43, 2360 (2002). https://doi.org/10.2320/matertrans.43.2360

15. A. Ayuela, J. Enkovaara, K. Ullakko, and R. M. Nieminen, J. Phys. Condens. Matt. 11, 2017 (1999). https://doi.org/10.1088/0953-8984/11/8/014

16. D. Pal, A. Ghosh, and K. Mandal, J. Magn. Magn. Mater. 360, 183 (2014). https://doi.org/10.1016/j.jmmm.2014.02.023

17. V. V. Khovaylo, V. D. Buchelnikov, R. Kainuma, V. V. Koledov, M. Ohtsuka, V. G. Shavrov, T. Takagi, S. V. Taskaev, and A. N. Vasiliev, Phys. Rev. B 72, ID 224408 (2005). https://doi.org/10.1103/PhysRevB.72.224408

18. M. Khan, J. Jung, S. S. Stoyko, A. Mar, A. Quetz, T. Samanta, I. Dubenko, N. Ali, S. Stadler, and K. H. Chow, Appl. Phys. Lett. 100, ID 172403 (2012). https://doi.org/10.1063/1.4705422

19. V. V. Khovailo, V. Novosad, T. Takagi, D. A. Filippov, R. Z. Levitin, and A. N. Vasil'ev, Phys. Rev. B 70, ID 174413 (2004). https://doi.org/10.1103/PhysRevB.70.174413

20. E. C. Passamani, F. Xavier, E. Favre-Nicolin, C. Larica, A. Y. Takeuchi, I. L. Castro, and J. R. Proveti, J. Appl. Phys. 105, ID 033919 (2009). https://doi.org/10.1063/1.3075835

21. M. Ye, A. Kimura, Y. Miura, M. Shirai, Y. T. Cui, K. Shimada, H. Namatame, M. Taniguchi, S. Ueda, K. Kobayashi, R. Kainuma, T. Shishido, K. Fukushima, and T. Kanomata, Phys. Rev. Lett. 104, ID 176401 (2010). https://doi.org/10.1103/PhysRevLett.104.176401

22. D. Pal and K. Mandal, Japan. J. Appl. Phys. 49, ID 073002 (2010). https://doi.org/10.1143/JJAP.49.073002

23. A. Ghosh and K. Mandal, J. Phys. D: Appl. Phys. 46, ID 435001 (2013). https://doi.org/10.1088/0022-3727/46/43/435001

24. S. Aksoy, M. Acet, P. P. Deen, L. Manosa, and A. Planes, Phys. Rev. B 79, ID 212401 (2009). https://doi.org/10.1103/PhysRevB.79.212401

25. M. Pasquale, C. P. Sasso, L. H. Lewis, L. Giudici, T. Lograsso, and D. Schlagel, Phys. Rev. B 72, ID 094435 (2005). https://doi.org/10.1103/PhysRevB.72.094435

26. X. Zhou, W. Li, H. P. Kunkel, and G. Williams, J. Phys. Condens. Matt. 16, L39-L44 (2004). https://doi.org/10.1088/0953-8984/16/6/L02 